\title{
Intrapancreatic accessory spleen false positive to 68Ga-Dotatoc: case report and literature review
}

\author{
Francesco Lancellotti ${ }^{1}$, Luca Sacco ${ }^{1}$, Saverio Cerasari ${ }^{1}$, Vittoria Bellato ${ }^{1}$, Simone Cicconi ${ }^{1}$, Antonio Ciardi ${ }^{2}$, \\ Edoardo Maria Muttillo ${ }^{1}$, Tiziana Feola ${ }^{3}$, Roberto Caronna ${ }^{1 *}$ (D) and Piero Chirletti ${ }^{1}$
}

\begin{abstract}
Background: Intrapancreatic accessory spleen (IPAS) is an uncommon finding of pancreatic mass. Differential diagnosis with pancreatic tumor, especially with non-functional neuroendocrine tumor (NF-NET), may be very hard and sometimes it entails unnecessary surgery. A combination of CT scan, MRI, and nuclear medicine can confirm the diagnosis of IPAS. 68-Ga-Dotatoc PET/CT is the gold standard in NET diagnosis and it can allow to distinguish between IPAS and NET.

Case presentation: A 69-year-old man was admitted to our hospital for an incidental nodule in the tail of the pancreas with focal uptake of 68-Ga-dotatate at PET/CT. NET was suspected and open distal splenopancreatectomy was performed. Pathologic examination revealed an IPAS.

Conclusion: This is the second IPAS case in which a positive 68Ga-Dotatoc uptake led to a false diagnosis of pancreatic NET. Here is a proposal of a literature review.
\end{abstract}

Keywords: Intrapancreatic accessory spleen, False positive to 68Ga-Dotatoc, Neuroendocrine tumor, Pancreatic mass

\section{Background}

Accessory spleen is a congenital abnormality consisting of normal splenic tissue in ectopic sites. It arises as a failure of fusion between some of the multiple buds of splenic tissue in the dorsal mesogastrium during embryologic life. This ectopic tissue can be found, in order of frequency in the following: splenic hilum $(80 \%)$, pancreatic tail (20\%), stomach, bowel, and genitals [1,2]. In autoptic studies, the accessory spleen has an incidence of $10 \%$ and IPAS of $2 \%$ [3], but clinical incidence, despite rare, is growing probably related to the improvement of diagnostic imaging accuracy. Rarely a specific abdominal pain or idiopathic thrombocytopenic purpura (not responsive to splenectomy) could be present in patients with IPAS [4]. Because asymptomatic, IPAS is almost always found incidentally as an undefined

\footnotetext{
* Correspondence: roberto.caronna@uniroma1.it

${ }^{1}$ Department of Surgical Sciences, Sapienza University of Rome, Viale del

Policlinico 155, 00161 Rome, Italy

Full list of author information is available at the end of the article
}

pancreatic mass similar to NETs [5]. The frequency of functional pancreatic NETs (F-P-NETs), similar to that of non-functional pancreatic NETs (NF-P-NETs), is probably increasing [5] due to the widespread use of high-quality imaging techniques [6]. Recent studies have shown imaging with 68-Ga-labeled somatostatin analogs with PET/CT to be highly sensitive and specific for PNETs [7]. We are illustrating a 69-year-old man with a mass in the tail of the pancreas found during his followup for previous sigmoid colon adenocarcinoma. Because of a positive result at 68-Ga-Dotatoc PET/CT and volumetric increasing of mass during follow-up, a P-NET was suspected.

\section{Case presentation}

A 69-year-old man with a past medical history significant for hypertension and sigmoid adenocarcinoma (UICC 2012: pT4 pN2 M0) underwent sigmoid colectomy and adjuvant chemotherapy (2015). No pancreatic mass was described at the computed tomography (CT) 

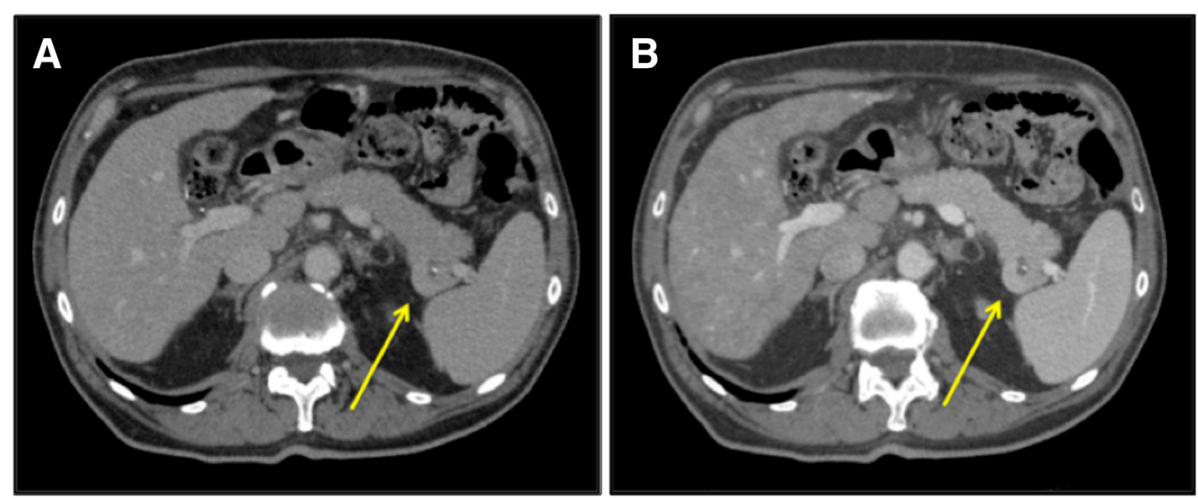

Fig. 1 Incidental mass in the tail of the pancreas (arrow). CT revealed a mass well delimited with homogeneous contrast enhancement. a Venous and $\mathbf{b}$ arterial phase axial CT images

images performed after colectomy. During the followup, a magnetic resonance imaging (MRI) showed a 1.5$\mathrm{cm}$ nodule of the pancreatic tail, non-homogeneous, hyperintense on T2-weighted and hypointense on T1weighted sequence, and a focal lesion inside hyperintense on T1. Endoscopic ultrasonography (EUS) revealed a $1.5-\mathrm{cm}$ anechoic nodule, with two hyperechoic foci ascribable to calcifications. The needle biopsy (EUSFNA) was not performed due to difficulties of endoscopic examination (the nodule was too far from the duodenal wall). 18-Fluorodeoxyglucose positron emission tomography ([18-F] FDG-PET) did not show FDG uptake.

Follow-up indication was given. After 8 months, this lesion showed a volumetric increase $(2 \mathrm{~cm})$ both at computed tomography (CT) and MRI (Fig. 1 and Fig. 2) without pathological uptake at FDG-PET. Tumoral markers (CA 19.9, CEA, alpha-fetoprotein) were negative. A 68Ga-Dotatoc PET/CT, more sensitive and specific for neuroendocrine tumor (NET), showed a focal area of uptake
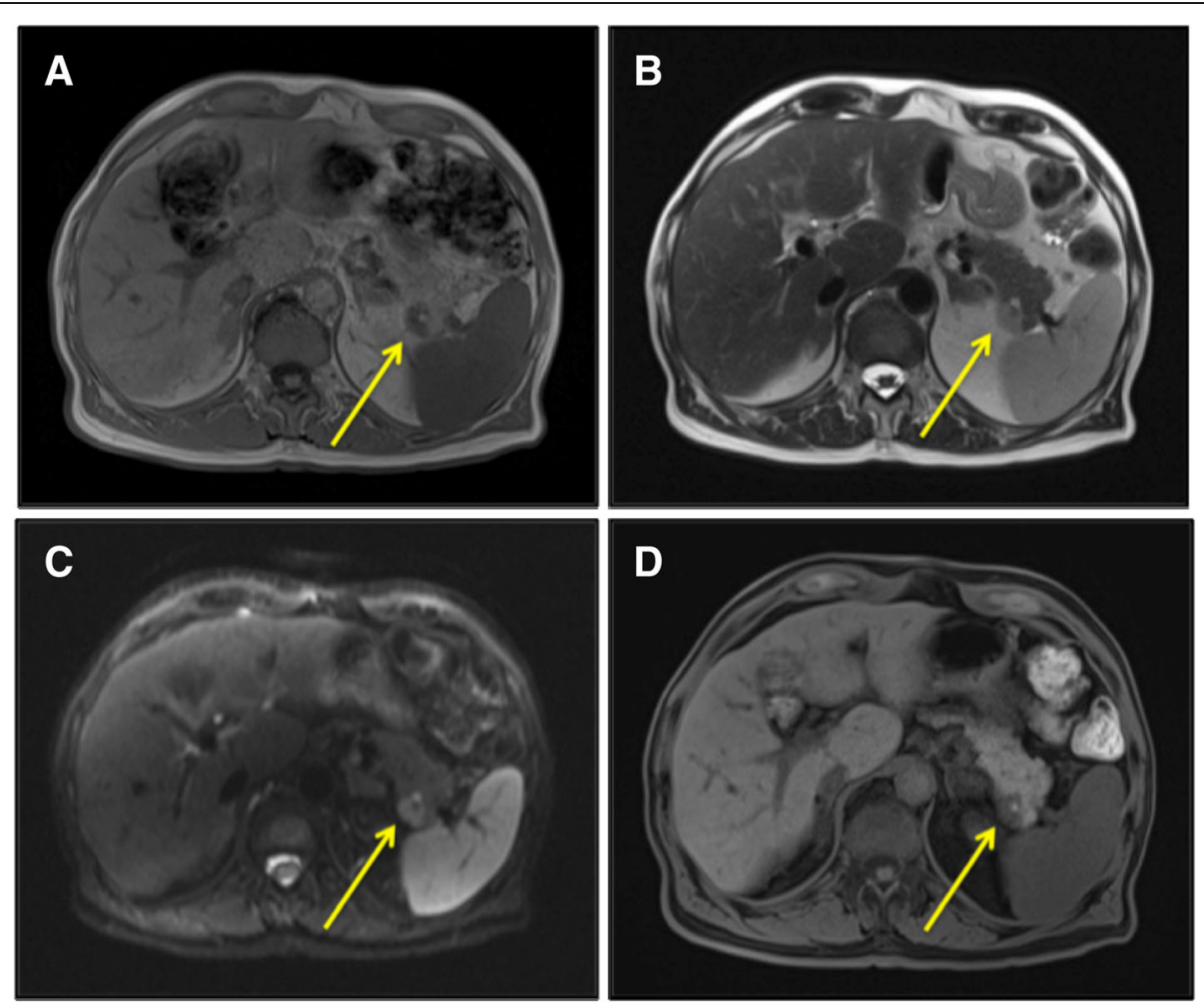

Fig. 2 MRI confirmed a 2-cm nodule of the tail of the pancreas hypointense on T1 (a) and hyperintense on T2 (b)-weighted sequence with a focal lesion inside hyperintense on T1. Diffusion-weighted MR imaging shows a high restriction (c) and hypointense in T1 fat sat sequence (d) 
(Fig. 3), but neuroendocrine markers (gastrin, chromogranin A, calcitonin, 5-hydroxytryptophan) were negative. Given the suspicion of NF-P-NET and close contact to splenic vessels, the patient underwent open distal splenopancreatectomy (Fig. 4) with an unremarkable postoperative course.

Definitive histologic examination revealed an intrapancreatic accessory spleen, with multiseptated epidermoid cyst (Fig. 5).

\section{Discussion}

In the English literature, there are, up to date, only 144 articles of which 115 are case reports concerning diagnosis and treatment of IPAS. From this data review, it was observed that most patients with IPAS underwent surgery without a preoperative definitive diagnosis and that IPAS was often put in differential diagnosis with NET or rarely with adenocarcinoma or metastatic tumors [8]. In Table 1, we report the literature results of diagnostic procedures performed, when clearly specified, in patients with IPAS [9-31]. Despite the high diagnostic accuracy of morphological and scintigraphic exams, IPAS was often unidentified and unnecessary surgery was performed in $66.6 \%$ of patients. False-negative results have been reported also after endoscopic ultrasonography-guided fine needle aspiration biopsy (EUS-FNA) and after Tc-99m heat-damaged red blood cell (HDRBD) scintigraphy.

The context is usually a CT/MRI incidental diagnosis of a nodule localized in the pancreatic tail, between 1 and $3 \mathrm{~cm}$, well-delimited, homogeneous, and hypervascular: IPAS should be suspected and more examinations required.

Tumoral and neuroendocrine markers have a limited role in the differential diagnosis. In pancreatic carcinoma, the most important tumoral markers are CA 19.9, CEA, CA125 (sensitivity of $81.3 \%, 39 \%$, and $56.4 \%$; specificity of $75.9 \%, 91.4 \%$, and $77.6 \%$ respectively) $[32,33]$.

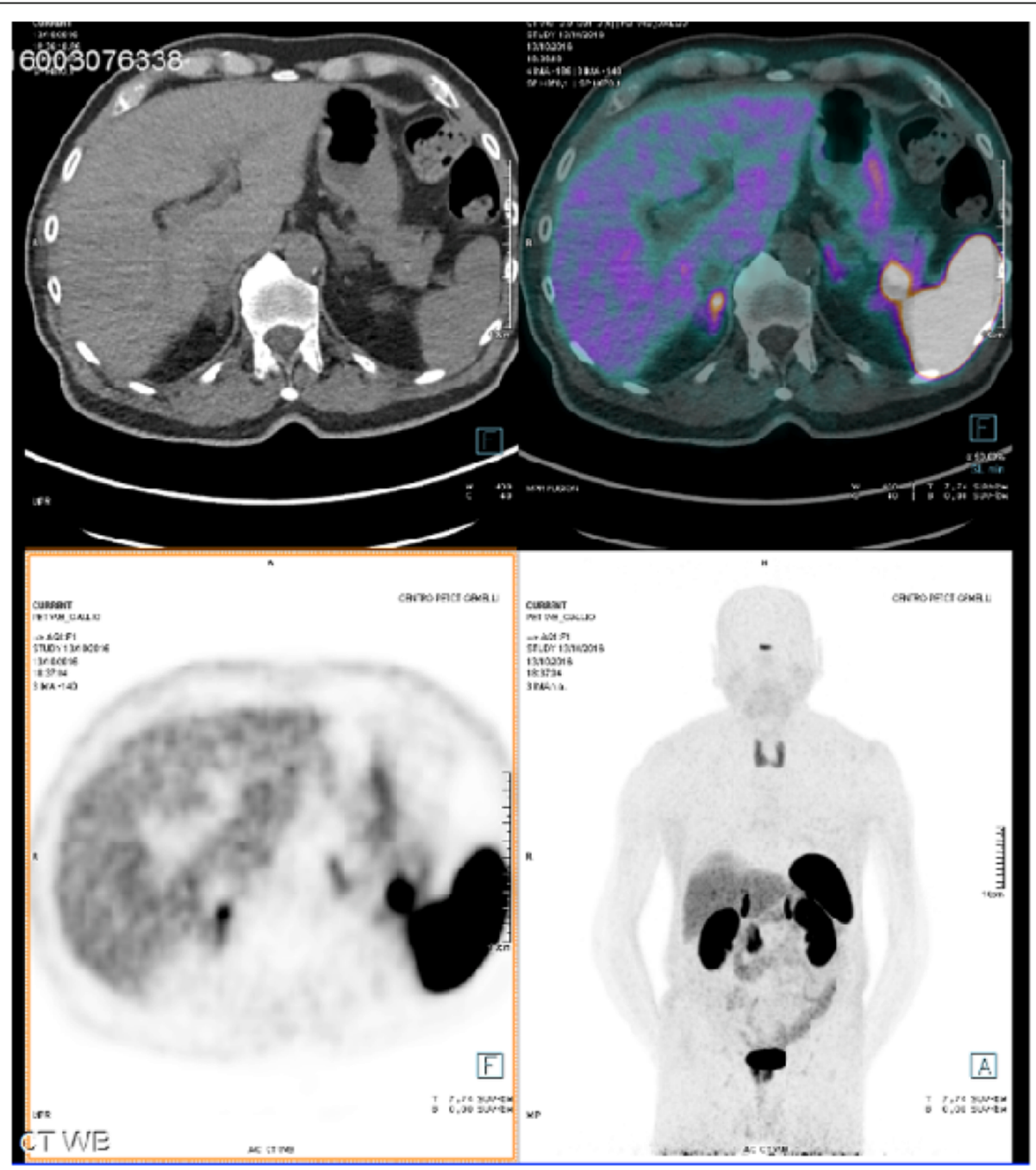

Fig. 3 The PET image shows an indeterminate pancreatic tail nodule with enhanced uptake of 68-Ga-dotatate at PET-CT fusion image (false positive) 


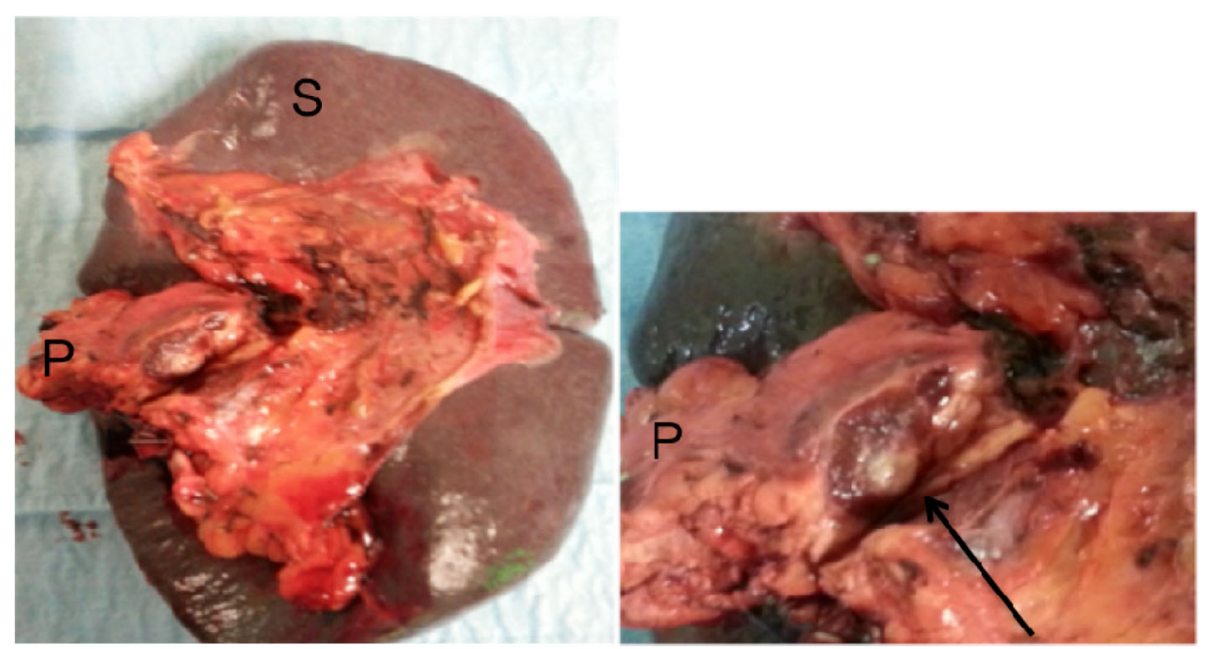

Fig. 4 Gross pathologic findings of IPAS: S the main spleen; P the tail of the pancreas. The arrow shows a reddish nodule with epidermoid cyst surrounded by pancreatic parenchyma

Approximately $50 \%$ of NET are non-functional tumors; in functional ones, neuroendocrine marker sensitivity is about $80 \%$ while specificity is much lower [34]. However, false-positive cases consisting of IPAS with increased tumoral and neuroendocrine markers have been reported $[10,13]$. Therefore, serological markers are not useful in the differential diagnosis between IPAS and NET or pancreatic carcinoma, as in our case.

For these reasons, a careful evaluation of the radiological images is very important.

At CT, IPAS shows attenuation and enhancement similar to the spleen in all phases, more than pancreatic parenchyma. Pancreatic tumors, instead, show a greater attenuation in the arterial phase and less in the venous phase $[13,19]$.

At MRI, IPAS often shows a low signal intensity in T1 and high intensity in T2 if compared to pancreatic parenchyma; moreover, intratumoral hemorrhage and necrosis are absent in IPAS [19]. The key to suspect IPAS at MRI is detecting the signal intensity of the mass similar to the spleen in all sequences [13]. On the other hand, Kim et al. demonstrated that sometimes IPAS signal intensity is slightly brighter than the spleen on the T2-weighted images, and this finding is due to the higher white-to-red pulp ratio of IPAS [13]. Recently, Jang et al. [23], in a retrospective study, have considered diffusion-weighted MRI (RMDW) value in the differential diagnosis between IPAS and solid pancreatic tumors of less than $3 \mathrm{~cm}$ showing a 90\% sensitivity and specificity. An Italian group in 2005 correctly diagnosed IPAS (without surgery), observing the same pattern of the spleen at CT and at MRI with reticuloendothelial systemspecific contrast medium (ferucarbotran), confirmed by mass stability after 16 months of follow-up [25].
Nuclear medicine has surely a role in IPAS diagnosis. Octreoscan and 68-Ga-PET/CT have been considered reliable in case of NET, while Tc- $99 \mathrm{~m}$ heat-damaged red blood cell (HDRBD) is specific for splenic tissue. According to variable expression NET somatostatin receptors (high or low), it is possible unfortunately unidentify these tumors only with radiolabelled somatostatin analog agent [35]. Furthermore, there are nontumoral processes (autoimmune diseases, pneumonias, etc.) and some tissues (spleen, kidney, thyroid, liver) that can have avidity for scintigraphy contrast, causing false positives. Octreoscan sensitivity and specificity for NET is about $80 \%$ while $68-\mathrm{Ga}$-Dotatoc seems to be superior (sensitivity and specificity range $80-100 \%$ ) [36]. Therefore, for NET diagnosis, the actual gold standard is 68Ga-PET-CT. To date, in the English literature, there is only one IPAS case in which a positive $68-\mathrm{Ga}-\mathrm{PET} / \mathrm{Tc}$ uptake led to a wrong diagnosis of pancreatic NET [1] probably due to physiological radioisotope uptake in splenic tissue (false positive) [30,37,38]. We present the second case of IPAS positive at $68-\mathrm{Ga}-\mathrm{PET} / \mathrm{CT}$. About 68-Ga-PET-CT sensitivity and specificity, it should be considered that the splenic tissue uptake of $68-\mathrm{Ga}-$ Dotatoc is highly variable $[39,40]$. The accuracy seems significantly higher for NET restaging than diagnosis [41] and then a histological confirmation for final diagnosis could be still considered [42]. Therefore, the diagnostic reliability of the 68-Ga-PET/TC in terms of differential diagnosis between NET and IPAS is still debated.

Technetium 99-m HDRBD scintigraphy is a specific technique for splenic tissue identification because of the physiological radioisotope uptake: focal uptake in the pancreatic tail suggests the presence of splenic intrapancreatic tissue [17]. Method limits are inferior spatial 

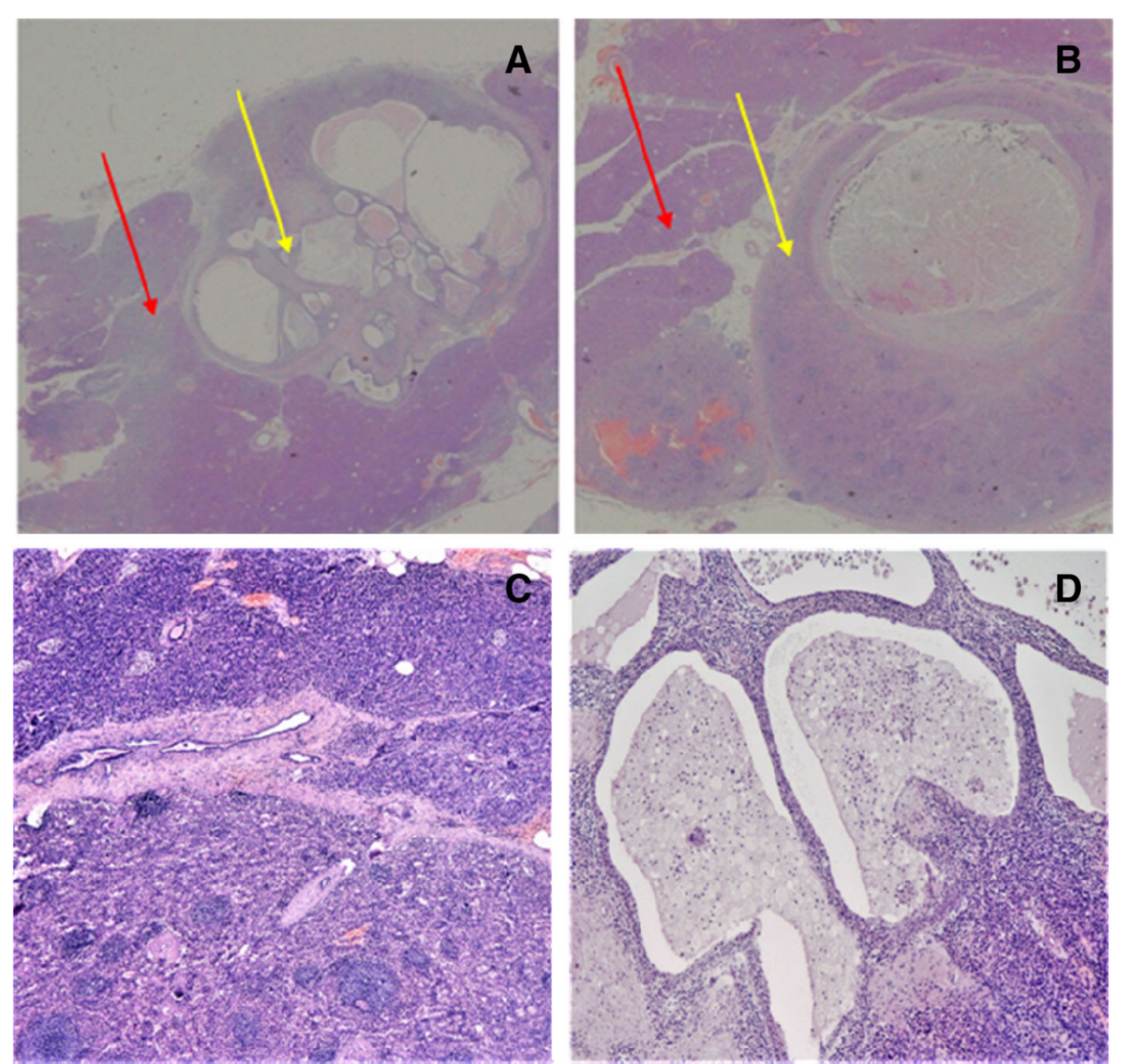

Fig. 5 Microscopic findings (hematoxylin and eosin staining). $\mathbf{a}, \mathbf{b}$ It is possible to observe the interface between pancreatic parenchyma (red arrow) and accessory spleen with epidermoid cyst (yellow arrow) $(H \& E, \times 4)$. c Histological picture of intrapancreatic splenic parenchyma with adjacent normal pancreas $(H \& E, \times 40)$. d Multiseptated intrasplenic epithelial cyst, with multilayered squamous epithelium $(H \& E, \times 40)$

resolution compared to other cross-sectional imaging modalities and need for a certain quantity of spleen functional ectopic tissue to visualize marked cells (cutoff dimension of $1.1 \mathrm{~cm}$ according to $\mathrm{Kim}$ et al.) [13]. Consequently, Tc-99m HDRBC scintigraphy is an exam that can be used as a confirmatory test for IPAS (positive predictive value) but false-negative results have been reported [19, 23, 31] (Table 1). In our case, it was not performed because $68-\mathrm{Ga}-\mathrm{PET} / \mathrm{TC}$ positive result was considered conclusive.

EUS-FNA, despite a certain rate of complications and false negatives, gives significant morphological and cytological informations. Schreiner et al. in 2008 first described a series of 3 IPAS identified by EUS, suggesting the need for a histologic diagnosis (FNA biopsy) in case of unconclusive imaging [14]. Cytological features for

Table 1 Literature review of 87 cases of IPAS confirmed by postoperative histological examination or by follow-up: diagnostic hypothesis and related surgical treatment [9-31]. Fifty-eight cases treated with surgery (66.6\%)

\begin{tabular}{|c|c|c|c|c|c|c|c|c|c|}
\hline \multirow[b]{3}{*}{ CT scan } & \multirow{3}{*}{$\begin{array}{l}\text { Patients, } \\
n \\
57\end{array}$} & \multicolumn{6}{|c|}{ Diagnostic hypothesis } & \multicolumn{2}{|c|}{ Unnecessary surgery } \\
\hline & & \multirow{2}{*}{$\frac{\text { IPAS }}{13}$} & \multirow{2}{*}{$\frac{U}{16}$} & \multirow{2}{*}{$\frac{\text { NET }}{24}$} & \multirow{2}{*}{$\frac{\text { Other }}{4}$} & \multicolumn{2}{|c|}{ Misleading, $n(\%)$} & \multirow{2}{*}{$\frac{n}{31}$} & \multirow{2}{*}{$\begin{array}{l}\% \\
54.3\end{array}$} \\
\hline & & & & & & 44 & $(77.1)$ & & \\
\hline MRI & 60 & 32 & 10 & 11 & 7 & 28 & $(46.6)$ & 40 & 66.6 \\
\hline EUS & 30 & 3 & 14 & 12 & 1 & 27 & (90) & 15 & 50 \\
\hline EUS-FNA & 20 & 15 & 2 & 3 & 0 & 5 & (25) & 8 & 40 \\
\hline Octreoscan & 9 & 0 & 7 & 2 & 0 & 2 & $(22.2)$ & 7 & 77.7 \\
\hline HDRBD & 10 & 6 & 0 & 4 & 0 & 4 & (40) & 6 & 60 \\
\hline
\end{tabular}


differential diagnosis of IPAS from other pancreatic nodules were described by Tatsas et al. [22]. In case of IPAS, there is a population of inflammatory cells (principally lymphocytes, but also monocytes, neutrophils, eosinophils) while immunocytochemical staining of CD8 specifically highlights endothelial cells of the thin-walled blood vessels [22]. EUS-FNA biopsy has a high (8090\%) sensitivity and specificity for pancreatic neuroendocrine tumors although its accuracy for such tumors is considered lower than the accuracy for pancreatic adenocarcinoma [21]. Although false-positive results have been reported $[11,16,31]$, the rate of unnecessary surgery after EUS-FNA biopsy is lower (40\%) compared with other morphological exams (Table 1). There is also the possibility of performing a contrast-enhancement EUS (CEUS) with intravenous contrast (Levovist or Sonazoid) without FNA: it may become the gold standard in IPAS diagnosis [43].

Finally, there is another method proposed for IPAS diagnosis: confocal laser endomicroscopy (CLE) [24]. CLE is an endoscopic technique which allows to obtain the mucosal images with a magnification of about $x$ 1000. This technique allows to identify cellular and subcellular microstructures and an in vivo histological diagnosis (optical virtual biopsy). The use of needle-based probe CLE prior to EUS-FNA in the diagnosis of pancreatic masses may increase diagnostic accuracy [24].

To date, there are no guidelines but recommended diagnostic algorithms to suspect and diagnose IPAS have been proposed by Spencer et al., Li et al., and Baugh et al. $[19,31,44]$.

\section{Conclusion}

In the differential diagnosis of solid nodules in the pancreatic tail, IPAS should always be considered. Besides increasing clinical incidence due to the improvement of imaging quality, it remains a non-neoplastic lesion with no surgical indication. IPAS should be suspected in the presence of some features: incidentally asymptomatic lesion, localization in the tail of the pancreas, dimension between 1 and $3 \mathrm{~cm}$, well-delimited homogeneous and hypervascular nodule, similar attenuation to the spleen on CT and MRI, negativity of neuroendocrine, and tumoral markers. A combination of CT, MRI, nuclear medicine examinations, and EUS-FNA biopsy could be necessary for a diagnosis of IPAS because none of them are individually conclusive. False positives or false negatives are possible, as in our clinical case with 68-Ga-Dotatoc PET/CT false positive.

\section{Abbreviations}

[18-F] FDG-PET: 18-Fluorodeoxyglucose positron emission tomography; CEUS: Contrast-enhancement EUS; CLE: Confocal laser endomicroscopy; CT: Computed tomography; EUS: Endoscopic ultrasonography; EUSFNA: Endoscopic ultrasonography-guided fine needle aspiration biopsy;
HDRBD: Tc-99m heat-damaged red blood cell; IPAS: Intrapancreatic accessory spleen; MRI: Magnetic resonance imaging; NF-NET: Non-functional neuroendocrine tumor

\section{Acknowledgements}

Not applicable.

\section{Authors' contributions}

All authors provided an intellectual contribution to this manuscript. PC made the conceptualization. FL and LS wrote the manuscript. EMM made the formal analysis. SC, VB, SC, and TF analyzed the literature and interpreted the patient data. AC confirmed the histopathological examination results. $\mathrm{RC}$ reviewed the clinical notes and edited the document. All authors read and approved the final manuscript.

\section{Funding}

The design and collection, analysis, interpretation of data, and writing of the manuscript have not been supported by any grant or fund.

Availability of data and materials

All data generated or analyzed during this study are included in this published article.

Ethics approval and consent to participate

Not applicable

\section{Consent for publication}

Informed consent was obtained from the patient.

\section{Competing interests}

The authors declare that they have no competing interests.

\section{Author details}

${ }^{1}$ Department of Surgical Sciences, Sapienza University of Rome, Viale del Policlinico 155, 00161 Rome, Italy. ${ }^{2}$ Department of Radiological Oncological and Pathological Sciences, Sapienza University of Rome, Viale del Policlinico 155, 00161 Rome, Italy. ${ }^{3}$ Department of Experimental Medicine, Sapienza University of Rome, Viale del Policlinico 155, 00161 Rome, Italy.

Received: 25 February 2019 Accepted: 28 June 2019

Published online: 09 July 2019

\section{References}

1. Bostanci EB, Oter V, Okten S, Küçük NO, Soydal C, Turhan N, et al. Intrapancreatic accessory spleen mimicking pancreatic neuroendocrine tumor on 68-ga-dotatate PET/CT. Arch Iran Med. 2016;19:816-9.

2. Kawamoto S, Johnson PT, Hall H, Cameron JL, Hruban RH, Fishman EK. Intrapancreatic accessory spleen: CT appearance and differential diagnosis. Abdom Imaging. 2012;37(5):812-27.

3. Halpert B, Gyorkey F. Lesions observed in accessory spleens of 311 patients. Am J Clin Pathol. 1959:32(2):165-8.

4. Bhutiani N, Egger ME, Doughtie CA, Burkardt ES, Scoggins CR, Martin RC 2nd, et al. Intrapancreatic accessory spleen (IPAS): a single-institution experience and review of the literature. Am J Surg. 2017;213(4):816-20.

5. Gastrointestinal Pathology Study Group of Korean Society of Pathologists, Cho MY, Kim JM, Sohn JH, Kim MJ, Kim KM, Kim WH, et al. Current trends of the incidence and pathological diagnosis of gastroenteropancreatic neuroendocrine tumors ( GEP-NETs ) in Korea 2000-2009: Multicenter Study. Cancer Res Treat. 2012;44(3):157-65

6. Halfdanarson TR, Rabe KG, Rubin J, Petersen GM. Pancreatic neuroendocrine tumors (PNETs): incidence, prognosis and recent trend toward improved survival. Ann Oncol. 2008;19(10):1727-33.

7. Falconi M, Eriksson B, Kaltsas G, Bartsch DK, Capdevila J, Caplin M, et al. ENETS consensus guidelines update for the management of patients with functional pancreatic neuroendocrine tumors and non-functional pancreatic neuroendocrine tumors. Neuroendocrinology. 2016;103(2):153-71.

8. Uchiyama S, Chijiiwa K, Hiyoshi M, Ohuchida J, Imamura N, Nagano M, et al. Intrapancreatic accessory spleen mimicking endocrine tumor of the pancreas: case report and review of the literature. J Gastrointest Surg. 2008; 12(8):1471-3. 
9. Ota T, Tei M, Yoshioka A, Mizuno M, Watanabe S, Seki M, et al. Intrapancreatic accessory spleen diagnosed by Technetium-99m heat damage red blood cell SPECT. J Nucl Med. 1997;38(3):494-5.

10. Läuffer JM, Baer HU, Maurer CA, Wagner M, Zimmermann A, Büchler MW. Intrapancreatic accessory spleen. A rare cause of a pancreatic mass. Int J Pancreatol. 1999;25(1):65-8.

11. Ardengh JC, de Paulo GA, Ferrari AP. EUS-guided FNA in the diagnosis of pancreatic neuroendocrine tumors before surgery. Gastrointest Endosc. 2004;60(3):378-84

12. Brasca LE, Zanello A, De Gaspari A, De Cobelli F, Zerbi A, Fazio F, et al. Intrapancreatic accessory spleen mimicking a neuroendocrine tumor: magnetic resonance findings and possible diagnostic role of different nuclear medicine tests. Eur Radiol. 2004;14(7):1322-3.

13. Kim SH, Lee JM, Han JK, Lee JY, Kim KW, Cho KC, et al. Intrapancreatic accessory spleen: findings on MR imaging, CT, US and scintigraphy, and the pathologic analysis. Korean J Radiol. 2008;9(2):162-74.

14. Schreiner AM, Mansoor A, Faigel DO, Morgan TK. Intrapancreatic accessory spleen: mimic of pancreatic endocrine tumor diagnosed by endoscopic ultrasound-guided fine-needle aspiration biopsy. Diagnostic Cytopathology. 2018;36(4):262-5

15. Belkhir SM, Archambaud F, Prigent A, Chaumet-Riffaud P. Intrapancreatic accessory spleen diagnosed on radionuclide imaging. Clin Nucl Med. 2009; 34(9):642-4.

16. Arkadopoulos N, Athanasopoulos P, Stafyla V, Karakatsanis A, Koutoulidis V, Theodosopoulos T, Karvouni E, Smyrniotis V. Intrapancreatic accessory spleen issues: diagnostic and therapeutic challenges. J Pancreas. 2009;10(4):400-5.

17. Lin J, Jing X. Fine-needle aspiration of intrapancreatic accessory spleen, mimic of pancreatic neoplasms. Arch Pathol Lab Med. 2010;134(10):1474-8.

18. Kurmann A, Michel JM, Stauffer E, Egger B. Intrapancreatic accessory spleen misdiagnosed as a nonsecreting endocrine tumor: case report and review of the literature. Case Rep Gastroenterol. 2010;4(2):210-4

19. Spencer LA, Spizarny DL, Williams TR. Imaging features of intrapancreatic accessory spleen. Br J Radiol. 2010;83(992):668-73.

20. Krishna SG, Heif MH, Sharma SG, Pandey T, Rego RF. Intrapancreatic accessory spleen: investigative dilemmas and role of EUS-guided FNA for diagnostic confirmation. J Pancreas. 2011;12(6):603-6.

21. Toussaint E, Flamen P, Demetter $P$, Matos C, Van Gossum M, Delhaye M et al. A rare case of a pancreatic mass due to accessory spleen; when EUS-FNA is not enough. Endoscopy. 2011;43 Suppl 2 UCTN:E221-2.

22. Tatsas AD, Owens $C L$, Siddiqui MT, Hruban RH, Ali SZ. Fine-needle aspiration of intrapancreatic accessory spleen: cytomorphologic features and differential diagnosis. Cancer Cytopathol. 2012;120(4):261-8.

23. Jang KM, Kim SH, Lee SJ, Park MJ, Lee MH, Choi D. Differentiation of an intrapancreatic accessory spleen from a small $(<3 \mathrm{~cm})$ solid pancreatic tumor: value of diffusion-weighted MR imaging. Radiology. 2013;266(1):159-67.

24. Bastidas AB, Holloman D, Lankarani A, Nieto JM. Endoscopic ultrasoundguided needle-based probe confocal laser endomicroscopy (nCLE) of intrapancreatic ectopic spleen. ACG Case Rep J. 2016;3(3):196-8.

25. Boraschi P, Donati F, Volpi A, Campori G. On the AJR viewbox. Intrapancreatic accessory spleen: diagnosis with RES-specific contrastenhanced MRI. AJR Am J Roentgenol. 2005;184(5):1712-3.

26. Yang B, Valluru B, Guo YR, Cui C, Zhang P, Duan W. Significance of imaging findings in the diagnosis of heterotopic spleen-an intrapancreatic accessory spleen (IPAS): case report. Medicine (Baltimore). 2017;96(52):e9040.

27. Matsumoto K, Kato H, Okada H. Epidermoid cyst in an intrapancreatic accessory spleen diagnosed by typical radiographic images and endoscopic ultrasound fine-needle aspiration findings with contrast agent. Clin Gastroenterol Hepatol. 2018;16(2):e13-4.

28. Uchida D, Tsutsumi K, Kato H, Okada H. An intrapancreatic accessory spleen that was difficult to diagnose due to temporal changes after splenectomy. Intern Med. 2018;57:681-5.

29. Val-Bernal JF, Martino M, Yllera-Contreras E, Castro-Senosiain B, Bueno-Ortiz P. Intrapancreatic accessory spleen. Report of four cases diagnosed by ultrasound-guided fine-needle aspiration biopsy. Rom J Morphol Embryol. 2018;59(2):619-24

30. Barber TW, Dixon A, Smith M, Yap KS, Kalff V. Ga-68 octreotate PET/CT and Tc-99m heat-denatured red blood cell SPECT/CT imaging of an intrapancreatic accessory spleen. Med Imaging Radiat Oncol. 2016;60(2): 227-9.
31. Baugh KA, Villafane N, Farinas C, Dhingra S, Silberfein EJ, Massarweh NN Cao HT, Fisher WE, Van Buren G. Pancreatic incidentalomas: a management algorithm for identifying ectopic spleens. J Surg Res. 2019;236:144-52.

32. Setoyama T, Natsugoe $\mathrm{S}$, Okumura $\mathrm{H}$, Matsumoto M, Uchikado $\mathrm{Y}$, Yokomakura $\mathrm{N}$, et al. Alpha-catenin is a significant prognostic factor than E-cadherin in esophogeal squamous cell carcinoma. J Surg Oncol. 2007;95(2):148-55.

33. Huang Z, Liu F. Diagnostic value of serum carbohydrate antigen 19-9 in pancreatic cancer: a meta-analysis. Tumour Biol. 2014;35(8):7459-65.

34. Modlin IM, Oberg K, Taylor A, Drozdov I, Bodei L, Kidd M. Neuroendocrine tumor biomarkers: current status and perspectives. Neuroendocrinology. 2014;100(4):265-77.

35. Balon HR, Brown TL, Goldsmith SJ, Silberstein EB, Krenning EP, Lang O, et al. The SNM Practice Guideline for Somatostatin Receptor Scintigraphy 2.0. J Nucl Med Technol. 2011;39(4):317-24.

36. Mojtahedi A, Thamake S, Tworowska I, Ranganathan D, Delpassand ES. The value of (68)Ga-DOTATATE PET/CT in diagnosis and management of neuroendocrine tumors compared to current FDA approved imaging modalities: a review of literature. Am J Nucl Med Mol Imaging. 2014;4(5):426-34

37. Suriano S, Ceriani L, Gertsch P, Crippa S, Giovanella L. Accessory spleen mimicking a pancreatic neuroendocrine tumor. Tumori. 2011;97(6):39e-41e.

38. García Angarita F, Sanjuanbenito DA. Intrapancreatic accessory spleen: a rare cause of recurrence of immune thrombocytopenic purpura. Clin Case Rep. 2016;4(10):979-81

39. Prasad V, Baum RP. Biodistribution of the Ga-68 labeled somatostatin analogue DOTA-NOC in patients with neuroendocrine tumors: characterization of uptake in normal organs and tumor lesions. Q J Nuc Med Mol Imaging. 2010;54(1):61-7.

40. Kagna O, Pirmisashvili N, Tshori S, Freedman N, Israel O, Krausz Y. Neuroendocrine tumor imaging with 68Ga-DOTA-NOC: physiologic and benign variants. AJR. 2014;203:1317-23.

41. Sharma P, Arora S, Dhull VS, Naswa N, Kumar R, Ammini AC, Bal C. Evaluation of $68 \mathrm{Ga}$-DOTANOC PET/CT imaging in a large exclusive population of pancreatic neuroendocrine tumors. Abdom Imaging. 2015; 40(2):299-309.

42. Mapelli P, Tam H, Sharma R, Aboagye E, Al-Nahhas A. Frequency and significance of physiological versus pathological uptake of 68Ga-DOTATATE in the pancreas: validation with morphological imaging. Nucl Med Commun. 2014;35(6):613-9.

43. Makino Y, Imai Y, Fukuda K, Seki Y, Kogita S, Sawai Y, et al. Sonazoidenhanced ultrasonography for the diagnosis of an intrapancreatic accessory spleen: a case report. J Clin Ultrasound. 2011;39(6):344-7.

44. Li BQ, Xu XQ, Guo JC. Intrapancreatic accessory spleen: a diagnostic dilemma. HPB. 2018;20(11):1004-11

\section{Publisher's Note}

Springer Nature remains neutral with regard to jurisdictional claims in published maps and institutional affiliations.

Ready to submit your research? Choose BMC and benefit from:

- fast, convenient online submission

- thorough peer review by experienced researchers in your field

- rapid publication on acceptance

- support for research data, including large and complex data types

- gold Open Access which fosters wider collaboration and increased citations

- maximum visibility for your research: over $100 \mathrm{M}$ website views per year

At $\mathrm{BMC}$, research is always in progress.

Learn more biomedcentral.com/submissions 